\title{
Correlation of in vitro infiltration with glioma histological type in organotypic brain slices
}

\section{S Palfi ${ }^{1,2}$, KR Swanson ${ }^{3}$, S de Boüard', F Chrétien ${ }^{4,5}$, R Oliveira', RK Gherardi ${ }^{4,5}$, JM Kros ${ }^{6}$, M Peschanski' and C Christov*,1,4}

'INSERM Unité 42I, IM3, Faculté de Médecine, 94010 Créteil, France; ${ }^{2}$ Service de Neurochirurgie, Hôpital Henri Mondor, 94010 Créteil, France; ${ }^{3}$ Departments of Pathology and Applied Mathematics, University of Washington and Laboratory of Neuropathology, Harboniew Medical Center, Seattle, Washington 98104-2499, USA; ${ }^{4}$ Service de Neuropathologie, Hôpital Henri Mondor, 9401 OCréteil, France; ${ }^{5}$ INSERM EMI 00.1 I, IM3, Faculté de Médecine, 94010 Créteil, France; ${ }^{6}$ Departments of Pathology and Neuro-Oncology, Erasmus University Medical Center, 3015 GD Rotterdam, The Netherlands

\begin{abstract}
Diffuse invasion of the brain, an intrinsic property of gliomas, renders these tumours incurable, and is a principal determinant of their spatial and temporal growth. Knowledge of the invasive potential of gliomas is highly desired in order to understand their behaviour in vivo. Comprehensive ex vivo invasion studies including tumours of different histological types and grades are however lacking, mostly because reliable physiological invasion assays have been difficult to establish. Using an organotypic rodent brain slice assay, we evaluated the invasiveness of 42 grade II-IV glioma biopsy specimens, and correlated it with the histological phenotype, the absence or presence of deletions on chromosomes $I p$ and $19 q$ assessed by fluorescent in situ hybridisation, and proliferation and apoptosis indices assessed by immunocytochemistry. Oligodendroglial tumours with $1 \mathrm{p} / \mathrm{I} 9 \mathrm{q}$ loss were less invasive than astrocytic tumours of similar tumour grade. Correlation analysis of invasiveness cell proliferation and apoptosis further suggested that grade II-III oligodendroglial tumours with $\mathrm{I} / \mathrm{I} / \mathrm{q}$ loss grow in situ as relatively circumscribed compact masses in contrast to the more infiltrative and more diffuse astrocytomas. Lower invasiveness may be an important characteristic of oligodendroglial tumours, adding to our understanding of their more indolent clinical evolution and responsiveness to therapy.

British Journal of Cancer (2004) 91, 745-752. doi:I0.1038/sj.bjc.6602048 www.bjcancer.com

Published online 3 August 2004

(c) 2004 Cancer Research UK
\end{abstract}

Keywords: glioma; invasion; organotypic brain slice cultures

Diffuse gliomas are composed of cells of astrocytic and oligodendrocytic phenotype (Louis et al, 2001). Accordingly, the main types of diffuse gliomas (referred to hereafter as to 'gliomas') are astrocytomas $(A s)$, oligodendrogliomas $(\mathrm{Ols})$, and mixed oligoastrocytomas (OlAs) (Kleihues et al, 2002). Malignancy of gliomas is assessed by histological grades (II-IV) depending on the presence of cellular pleomorphism, mitosis, vascular proliferation, and necrosis (Kleihues et al, 2002). The most malignant grade IV tumours, multiform glioblastomas (GBMs), are associated with a median survival of less than 12 months. Even grade II gliomas, however, are ultimately lethal, because of relentless progression to higher grade. Importantly, local treatments of tumours of all grades fail because gliomas are highly invasive (Giese et al, 2003). Thus, surgery fails since the tumour recurs inevitably at the infiltrated margin, no matter how much margin has been resected (Chicoine and Silbergeld, 1995; Silbergeld and Chicoine, 1997).

Since invasiveness is largely responsible for the dismal outcome of glioma patients, its cellular and molecular mechanisms (Giese

\footnotetext{
*Correspondence: Dr C Christov, INSERM Unité 42I, IM3, Faculté de Médecine, 8 rue du Général Sarrail, 94010 Créteil, France; E-mail: christov_christo@hotmail.com

Received 9 December 2003; revised 19 May 2004; accepted 19 May 2004; published online 3 August 2004
}

et al, 2003) and kinetics (Burgess et al, 1997) have been intensively studied. From a kinetic point of view, glioma invasion of the brain is defined as a major determinant of glioma growth (Burgess et al, 1997; Swanson et al, 2000, 2002). Glioma growth involves two independent determinants: infiltrative, resulting from tumour cell spread in the brain parenchyma, and in situ proliferative, the net result of cell division and apoptosis (Burgess et al, 1997).

Although highly desirable as a basis to assess the infiltrative growth potential of glioma biopsies (Burgess et al, 1997), data on glioma invasiveness in primary culture are scarce (for a review, see De Boüard et al, 2002). This is particularly true for grade II and III gliomas, of which less than 25 cases have been studied (De Boüard et al, 2002). Results from these studies, obtained with different invasion assays, are often contradictory. Moreover, it is now admitted that some of these assays fail to mimic the in vivo environment of gliomas, and probably provide biased estimates of invasiveness (Jung et al, 2001; De Boüard et al, 2002). We developed, on the basis of techniques recently described using glioma cell lines (Jung et al, 2001; Murakami et al, 2001), an assay wherein glioma biopsy fragments are implanted into rodent brain slices (De Boüard et al, 2002). This organotypic assay, in which invasive glioma cells show patterns of dissemination and phenotypes similar to those in vivo, also allows studying quantitatively the invasive potential of gliomas of different types and grades. 
In this study, we assessed the ex vivo invasive potentials of 42 glioma biopsy specimens and explored by multivariate analysis their relationships with established parameters of glioma prognosis, such as histological type and grade, presence or absence of deletions on chromosomes $1 \mathrm{p}$ and $19 \mathrm{q}$ (Louis et al, 2001), tumour cell proliferation and apoptosis (Rhodes, 1998), vascularisation, and cell density (McKeown and Ramsay, 1996). The main result of this analysis is that Ols and mixed OlAs are less invasive than purely astrocytic tumours of similar malignancy grade. In Discussion, we offer a perspective on glioma invasion, emphasising its interplay with in situ proliferation and the potential consequences of this interplay for glioma growth.

\section{MATERIAL AND METHODS}

The analysis included biopsies from 51 patients (42 grade II-IV gliomas, two grade I gangliogliomas, a choroid plexus papilloma, two meningiomas, two squamous-cell lung carcinoma brain metastases, and two gliosis specimens associated with primary vasculitis of the brain and an arachnoid cyst). One biopsy fragment was processed for cell culture as described below, and a second one was submitted for histopathological analysis. Quantification of $1 \mathrm{p} /$ $19 \mathrm{q}$ status, histological features, cell proliferation, and apoptosis was carried out on paraffin sections of the second fragment.

\section{Histological classification of gliomas}

Gliomas were classified by the guidelines of the WHO 2000 classification (Kleihues et al, 2002). Mixed OlAs were tumours in which the two cell populations with oligo- and astroglial phenotype were topographically separated, at least in some areas (Bigner et al, 1999); this definition basically corresponds to the biphasic OlAs in the WHO 2000 classification. Glioblastomas with oligodendroglial component (GOCs) (Bigner et al, 1999; Kleihues et al, 2002) were biphasic tumours with grade IV histological features.

Slides were first examined separately by three pathologists (CC, FC, and RG), and then in several sessions using a multi-head microscope, until a consensus diagnosis was reached.

\section{Immunohistochemistry}

The following primary monoclonal (MC) and polyclonal (PC) antibodies were applied $\left(12-16 \mathrm{~h}\right.$ at $\left.4^{\circ} \mathrm{C}\right)$ to deparaffinised $5 \mu \mathrm{m}$ sections of neutral formalin-fixed specimens, with or without antigen retrieval $(\mathrm{AR})$ (microwave treatment $(3 \times 5 \mathrm{~min})$ in citrate buffer (pH 6.0)): anti-GFAP (PC, 1:100, Dako, Glostrup, Denmark), anti-Ki67 (MIB-1) (MC, 1:50, Immunotech, Marseilles, France) (AR), anti-active human caspase 3 (PC, $1: 2000, \mathrm{R} \& \mathrm{D}$ Systems, Abingdon, UK) (AR), and anti-CD34 (MC, 1:200) (Dako). Bound primary antibodies were detected by a Vector Elite ABC kit (Vector Laboratories, Burlingame, CA, USA) following the manufacturer's instructions with $\mathrm{DAB}$ as the chromogen and haematoxylin counterstain. The anti-caspase 3 antibody was detected by an FITC-conjugated secondary antibody (1:500, Jackson ImmunoResearch, Philadelphia, PA, USA), and slides were counterstained with DAPI $\left(10 \mu \mathrm{g} \mathrm{ml}^{-1}\right)$. Negative controls had the primary antibody omitted. In 13 cases, apoptosis was also detected by an ApopTag ${ }^{\mathbb{R}}$ kit (Intergen, Purchase, NY, USA) according to the manufacturer's instructions. Values of caspase 3 and ApopTag ${ }^{\mathbb{B}}$ labeling indices (LIs), determined as outlined below, were concordant $(1.8 \pm 1.7$ vs $1.9 \pm 1.6 \%)$ and tended to be positively correlated $(\rho=0.56, P=0.053)$. Owing to high variability of nuclear staining intensity with ApopTag ${ }^{\mathbb{B}}$ (Rhodes, 1998), the more easy-to-read caspase 3 immunolabelling was preferred (Figure 1A, B).
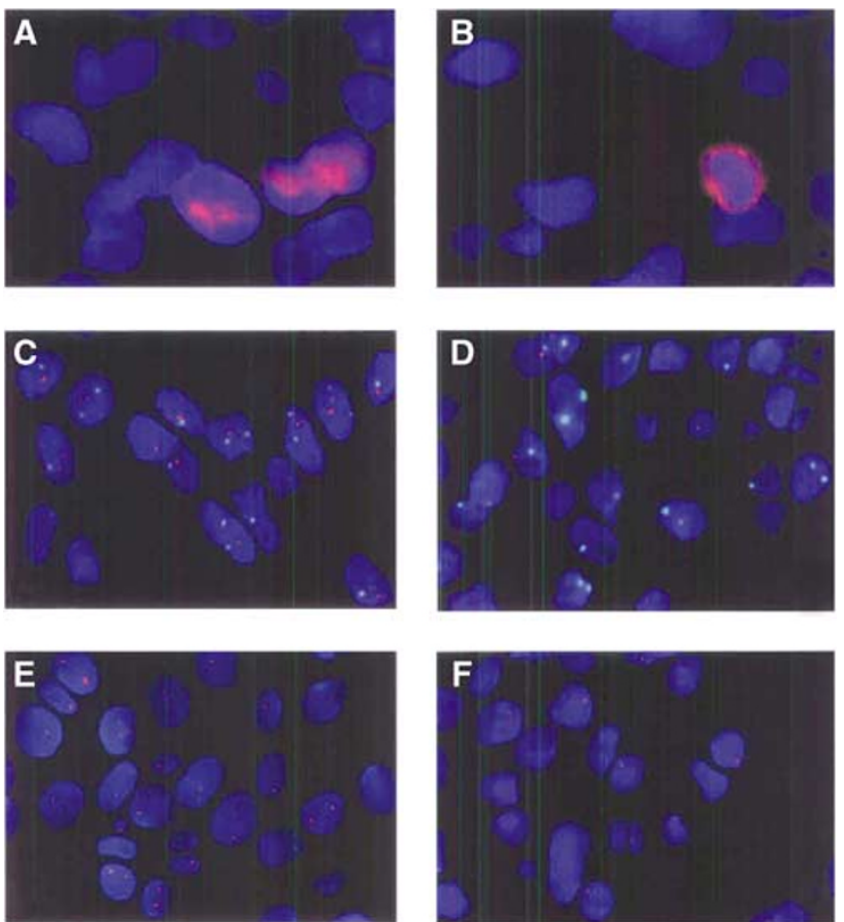

Figure I Nuclear (A) and cytoplasmic (B) active caspase 3 immuno labellings. For the purposes of this illustration, bound anti-caspase 3 primary antibody was detected by a biotinylated secondary antibody, an avidinperoxidase complex (both from Vector), and the TSA cyanine 3 signal amplification system (PerkinElmer ${ }^{\mathrm{TM}}$, Boston, USA). Separately acquired images in the red and blue (DAPI) channels were subjected to a shading correction by subtracting from the original image its version blurred by a 50-fold application of a 46-size lowpass filter, and mildly deconvoluted using the iterative optical deconvolution module of KS400 3.0 with 10 itinerations of a maximum likelihood algorithm and suitable aperture values. $\mid \mathrm{p} / \mathrm{lc}(\mathbf{C}, \mathbf{D})$ and $19 \mathrm{q}(\mathbf{E}, \mathbf{F})$ showing representative fields of tumours without $(\mathbf{C}, \mathbf{E})$ and with $(\mathbf{D}, \mathbf{F})$ chromosomal losses. Note that, for the simultaneous identification of two probes (e.g. I p/lc), nine patterns of labelling ranging from $(0,0)$ to $(2,2)$ are possible. All except $(2,2)$ can be due to nuclear truncation. We attempted to control for these inevitable artefacts by applying the two methods outlined in Figure 2. To cut cytoplasmic background staining and to safely overamplify probe signals, FISH images represent field reconstructions of nuclei projected upon an artificial black background.

\section{Quantitative analysis of proliferation, apoptosis, and histological features}

All quantitative analyses were carried out using different modules of the KS400 3.0 image analysis software (Zeiss, Germany) on microscopic images digitised with a Coolsnap 300 camera (Roper Scientific, Tucson, AZ, USA) coupled to an Axioplan 2 microscope (Zeiss).

On histological sections, the Ki-67 (MIB-1) and active caspase 3 LIs (Schiffer et al, 2001), and tumour cell densities (cells $\mathrm{mm}^{-2}$ ) were estimated in 10-15 microscopic fields $(\times 400)$ (at least 1000 tumour cells) in a representative tumour zone. The proliferation/ apoptosis (MIB1/caspase 3) ratios assessing the in situ growth potential of a glioma (Rhodes, 1998) were calculated for 37 tumours. Vessel density was evaluated on CD34-immunostained sections by image analysis (Guillamo et al, 2001). Compact tumour areas ( $>90 \%$ of tumour cells) and diffuse areas where tumour cells intermingled with host cells were interactively marked in the image graphics plane and their respective proportions calculated. 


\section{Fluorescence in situ hybridisation (FISH) for $1 \mathrm{p}$ and $19 \mathrm{q}$}

Dual-probe FISH on $5 \mu \mathrm{m}$ paraffin sections (39 gliomas and four brain specimens free of tumour) was carried out with differentially labelled probes for 1p36 (D1S32), centromere 1 (1c) (pUC1.77); all specimens with $1 \mathrm{p}$ loss were subsequently tested with a locusspecific probe for 19q13 (BAC2310A1). FISH was performed as previously described with modifications (Van den Bent et al, 2003). Briefly, probes were nick-labelled with biotin-16-dUTP or digoxigenin-11-dUTP (Roche Diagnostics, Almere, The Netherlands). Deparaffinised sections $(4 \mu \mathrm{m})$ were microwave-treated $(5 \mathrm{~min})$ in citrate buffer $(\mathrm{pH} 6.0)$, digested with pepsin solution (Sigma) $(0.005 \%$ in $0.1 \mathrm{M} \mathrm{NaCl}, \mathrm{pH} 1.5)(20 \mathrm{~min})$ at $37^{\circ} \mathrm{C}$, dehydrated in alcohols (70, 90, and 100\%), and air-dried. The probes were applied to the slides, and probes and specimen DNA were simultaneously denatured at $80^{\circ} \mathrm{C}(3 \mathrm{~min})$. Hybridisation was carried out overnight (BAC2310A1) or over $48 \mathrm{~h}$ (D1S32 and pUC1.77). Following washes in $1.5 \mathrm{~m}$ urea/ $0.1 \times \mathrm{SSC}$ at $45^{\circ} \mathrm{C}$ $(15 \mathrm{~min})$ and in Tween $0.1 \% / 2 \times$ SSC $(5 \mathrm{~min})$, slides were exposed to a FITC-conjugated sheep antibody $(1: 50)$ and Cy3-conjugated avidin (1:100) (Roche Diagnostics) in PBS at $37^{\circ} \mathrm{C}(20 \mathrm{~min})$, washed twice in Tween $0.1 \% / 2 \times$ SSC, counterstained with DAPI, and mounted in antifade solution. Signals (60-100 nonoverlapping nuclei per specimen) were counted on a Leica DM RXA microscope equipped with single- or triple-pass filtres (DAPI/ FITC/Cy3) (Figure 1C-F). 1p/19q loss was evaluated by two methods adapted to eliminate errors due to sectioning of nuclei. The mean $1 \mathrm{p} / 1 \mathrm{c}$ signal ratio $\left(x_{1 \mathrm{p} / 1 \mathrm{c}}\right)$ of the nontumour specimens was calculated. Tumours with ratios less than $x_{1 \mathrm{p} / 1 \mathrm{c}}-3 \mathrm{SD}$ were considered abnormal (Figure 2A). Additionally, for each specimen, the cumulative counts of $1 \mathrm{p}$ and $1 \mathrm{c}$ (reference) signals were compared by the Kolmogorov-Smirnov test (Figure 2B). These two methods yielded identical results. To estimate $19 \mathrm{q}$ loss, for which no reference probe was available, the cumulative signal count of each tumour was compared with the mean cumulative count of the nontumour specimens (Figure 2C).

\section{In vitro invasion assay}

The invasion assay was performed as previously described (De Boüard et al, 2002). Briefly, $400 \mu \mathrm{m}$ coronal slices cut from the brains of 7-days-old C57/bl6 mice were deposited onto MillicellCM membranes (Millipore, France) and maintained above $1 \mathrm{ml}$ of medium (minimum essential medium (MEM) (Gibco, France), $1 \mathrm{gl}^{-1}$ D-glucose, $10 \%$ foetal calf serum, $0.1 \mathrm{gl}^{-1}$ transferrin, $16 \mu \mathrm{gl}^{-1}$ putrescin, $40 \mu \mathrm{gl}^{-1} \mathrm{~N}$-selenium, $30 \mu \mathrm{gl}^{-1}$ tri-iodothyronin, $5 \mathrm{mgl}^{-1}$ insulin, and $60 \mu \mathrm{gl}^{-1}$ progesterone) in a standard cell incubator. Fragments $(0.1-0.4 \mathrm{~mm})$ containing histologically verified viable tumour tissue were incubated in $30 \mu \mathrm{g} \mathrm{ml}^{-1}$ DiI (1,1'-dioctadeccyl-3,3,3', $3^{\prime}$,-tetramethylindocarbocyanine perchlorate) (Molecular Probes, Eugene, OR, USA) for $24 \mathrm{~h}$ and implanted in the thickness of the slice. A median of $10(2-16)$ slice cultures was studied per case. At 15 days post culture, slices were fixed in $4 \%$ paraformaldehyde $\left(4 \mathrm{~h}\right.$ at $\left.4^{\circ} \mathrm{C}\right)$, removed from the filtre membrane, and mounted in antifade medium Fluoromount G, (Interchim, France). Animal studies were carried out in accordance with institutional guidelines for the care, and in agreement with the general recommmendations of the UKCCCR Guidelines for the Welfare of Experimental Animals (1998).

\section{Quantitative analysis of distance and cell density of invasion}

Distances of invasion of individual cells from the implant margin (Figure 3) were measured in the point measurement mode of KS

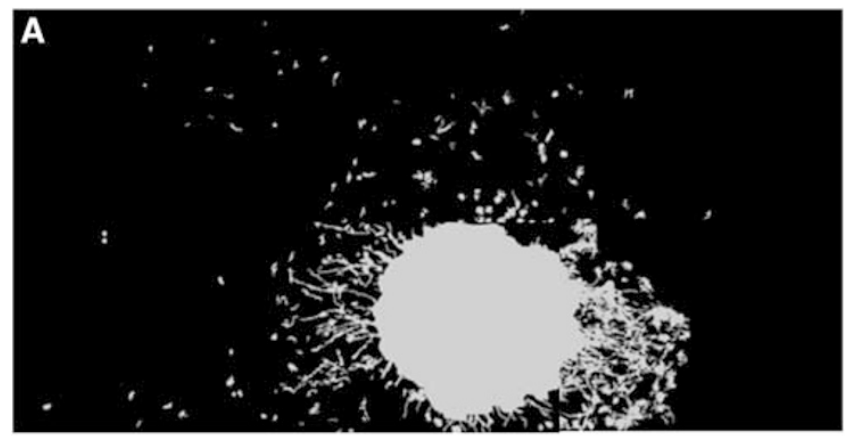

\section{B} $200 \mu \mathrm{m}$

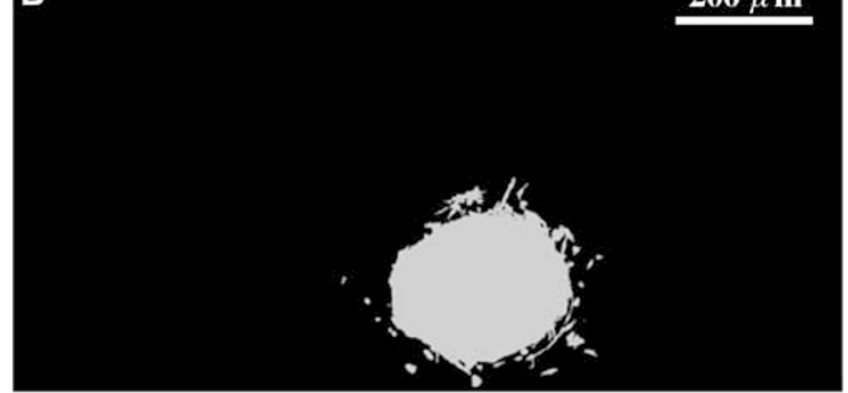

Figure 3 Examples of an invasive $(\mathbf{A})$ and a practically noninvasive (B) tumour in a brain slice. Each of the two image montages is composed of six contiguous microscopic fields $\left(\times 100,0.76 \mathrm{~mm}^{2}\right)$. To avoid out-of-focus fluorescent glow and to facilitate tumour cell recognition, each image of glioma cells was separately segmented using grey morphology and adaptive thresholding algorithms (KS400 3.0), and the resulting binary image was overlaid in grey.
A

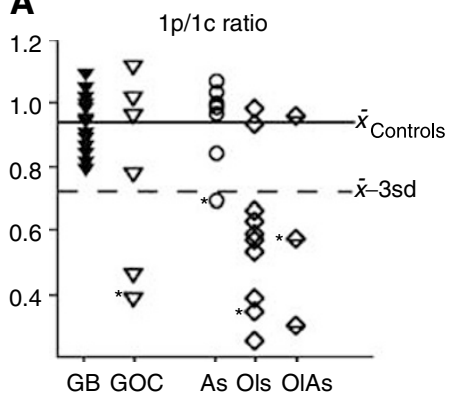

B

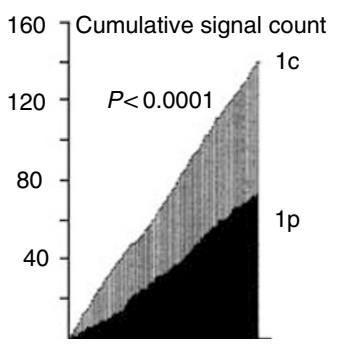

C

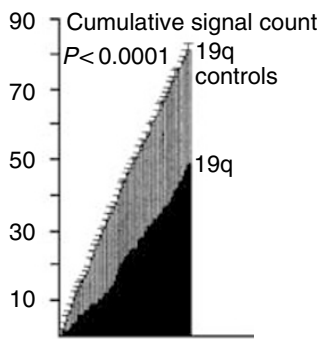

Figure 2 (A) I p loss ( I c: centromeric probe) in 39 gliomas: tumours with I $/$ / I values below the mean - 3s.d. threshold were considered to have I $p$ loss. Tumours with ratios below this threshold not marked with an asterisk (*) also had $19 \mathrm{q}$ loss. I p loss was detected in 12 out of 19 oligodendroglial and in one out of 20 astrocytic tumours ( $P<0.0003)$; I / / 9q loss in nine out of 19 oligodendroglial and in zero out of 20 astrocytic tumours $(P<0.0006)$. Four normal brain specimens were used to calculate the threshold. An example of a grade II OI with a I $/ \mathrm{I} 9 \mathrm{q}$ loss estimated by comparison of I p signals with I c signals in the same specimen (B), or of 19q signals with the mean 19q signal counts in the control group (C) (Kolmogorov-Smirnov test). 
400 3.0. In each case, the maximal distance of invasion $\left(D_{90}\right)$ was assessed by the 90th percentile calculated from the distribution of all invasive cells (median $n=1923$, range: $257-4766$ for GBMs, $n=396$, range: $48-1215$ for grade II and III gliomas).

The maximal cell density of invasion as a function of the invasion distance $\left(C_{90}\right)$ was assessed by first calculating the 90 th percentile of the density of invading cell (cells $\mathrm{mm}^{-2}$ ) at every $100 \mu \mathrm{m}$ increment of migration distance. Then, $C_{90}$ of each tumour was calculated in arbitrary units (AU) as the area under the curve of maximal cell densities of invasion. $D_{90}$, assessing the outer boundary of invasive cell spread, and $C_{90}$, assessing the maximal number of invading cells per unit area, are obviously two complementary characteristics of invasion (Figure 4).

\section{Statistics}

Statistical analysis was performed using StatView F-4.11 (Abacus Concepts, Berkeley, CA, USA) and GraphPad 3.00 (GraphPad Software, San Diego, CA, USA). Two groups were compared by the Mann - Whitney test and three groups by the Kruskall-Walis test. Correlations were evaluated by the Spearman test $(\rho)$, correlation analysis $(r)$, or the Fisher exact test. Principal component analysis (PCA) was used to illustrate the relationship between invasion, $1 \mathrm{p} /$ 19q loss, in situ growth, and several quantitatively evaluated histological features in grade II and III gliomas. Principal component analysis summarises information contained in many correlated variables as a few uncorrelated factors (principle components), thus facilitating the comprehension of complex relationships (McKeown and Ramsay, 1996). Using standard techniques (StatView F-4.11), the number of factors extracted was set to account for more than $80 \%$ of data variation and axes were rotated by a Varimax/Orthotran transformation. Data in the text are presented either as mean \pm standard deviation, or as median (range).

\section{RESULTS}

\section{Tumour histology and $1 \mathrm{p} / 19 \mathrm{q}$ status}

We examined 21 grade IV (14 purely astrocytic GBMs, six GOCs, one giant-cell GBM) and 21 grade II and III gliomas (As: grade II, $n=4$, grade III, $n=4$; Ols: grade II, $n=4$, grade III, $n=6$; OlAs: grade II, $n=1$, grade III, $n=2$ ). FISH was successfully carried out on 39 grade II-IV tumours. In these 39 tumours, and in the subgroup of grade II and III tumours $(n=20), 1 \mathrm{p}$ loss $(P<0.0003$ and 0.008$)$ and combined $1 \mathrm{p} / 19 \mathrm{q}$ loss $(P<0.006$ and 0.007$)$ were strongly associated with oligodendroglial differentiation (Figure 2A).

\section{Invasion in relation to tumour phenotype}

All gliomas showed variable numbers of invasive tumour cells within the slice tissue (Figure 3). Specimens from tumours other than gliomas were noninvasive in the slice assay.
Grade IV tumours showed higher $D_{90}$ and higher $C_{90}$ than grade II and III tumours (Figure 5), mostly because of higher $C_{90}$ values (Figure 5B), since $D_{90}$ values overlapped partially (Figure 5A). When cases in the overlap zone in Figure $5 \mathrm{~A}$ were separately examined, grade IV $(n=12)$ still showed higher $C_{90}$ than grade II and III $(n=10)$ tumours: $94(26-158)$ AUs vs $59(19-121)$ AUs $(P<0.006)$. Grade II and grade III tumours were similarly invasive (data not shown).

Within the group of grade II and III tumours, $D_{90}$ and $C_{90}$ were lower for Ols and OlAs than for As (Figure 5C, D). Since oligodendroglial differentiation was highly predictive of $1 \mathrm{p}$ or $1 \mathrm{p} /$ $19 \mathrm{q}$ loss, tumours harbouring these deletions also showed lower $D_{90}$ and $C_{90}$ than nondeleted tumours (data not shown). Within the group of grade IV tumours, $C_{90}$ was lower for GOCs than for GBMs (Figure 5F), while the difference in $D_{90}$ was not significant (Figure 5E).

This difference in $C_{90}$ was largely due to different cell densities of invasion within $0.5 \mathrm{~mm}$ away from the implants. According to $C_{90}$ in this zone, tumours could be subdivided into three patterns (Figure 4): high $\left(200 \leqslant C_{90} \leqslant 400\right.$ cells $\mathrm{mm}^{-2}$ ) (nine GBMs); intermediate $\left(100 \leqslant C_{90} \leqslant 200\right.$ cells $\mathrm{mm}^{-2}$ ) (five GBMs, three GOCs), and low $\left(C_{90} \leqslant 100\right.$ cells $\mathrm{mm}^{-2}$ ) (three GOCs and the giant cell GBM).

The giant cell GBM, an unusually indolent tumour, which has not progressed for 2 years after biopsy and irradiation, was minimally invasive $\left(D_{90}=0.576 \mathrm{~mm} ; C_{90}=52 \mathrm{AU}\right)$ and was excluded from further analyses.

\section{Invasion in relation to histological features and $1 \mathrm{p} / 19 \mathrm{q}$ loss in grade II and III gliomas}

$D_{90}$ was inversely correlated with $1 \mathrm{p} / 19 \mathrm{q}$ loss $(r=-0.64$; $P<0.002)$, cell density $(r=-0.66 ; P<0.0007)$, vessel density $(r=-0.49 ; P<0.03)$, and the MIB1/caspase 3 ratios $(r=-0.45$; $P<0.05$ ), and positively correlated with proportion of diffuse areas $(r=0.56 ; P<0.007) .1 \mathrm{p} / 19 \mathrm{q}$ loss was positively correlated with cell density and negatively with diffuse areas $(P<0.03)$. Cell or vascular density, and the MIB1/caspase 3 ratios were significantly positively associated among themselves $(0.43<r<0.60)$, while the proportion of diffuse areas was significantly negatively correlated with cell density $(r=-0.72)$, and the MIB1/caspase 3 ratios $(r=-0.47)$. A correlation matrix revealed correlations in 12 out of 15 pairs, three factors were extracted that accounted for over $80 \%$ of the variance, communality was $0.79-0.89$, sampling adequacy was $78 \%$, and factor structure simplicity was satisfactory. Factors loadings (Table 1) translated into three patterns of growth: 'vascular and in situ proliferative' (factor 1), 'hypercellular and compact (not diffuse)' (factor 2), and 'noninvasive, characteristic of tumours with $1 \mathrm{p} / 19 \mathrm{q}$ loss (factor 3 ). Ols and OlAs had higher factor scores than As for all the three factors (Figure 6). Thus, correlation analysis of invasiveness, in situ growth, and histological features suggests that grade II and III oligodendroglial tumours with $1 \mathrm{p} / 19 \mathrm{q}$ loss may tend to grow in situ as more circumscribed and more vascular masses, in contrast to the more diffuse, infiltrative, and less bulky As.
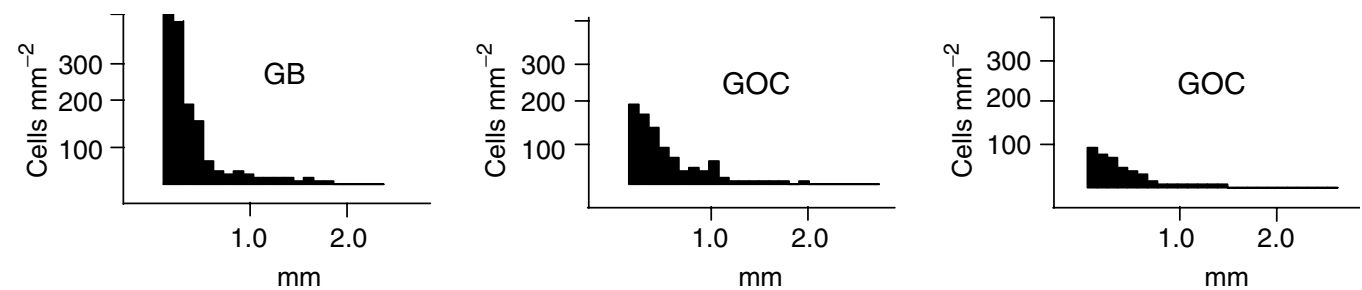

Figure 4 Representative examples of the three patterns of maximal cell density of invasion $\left(C_{90}\right)$ in grade IV tumours: high $\left(200 \leqslant C_{90} \leqslant 400\right.$ cells mm $\left.{ }^{-2}\right)$ intermediate $\left(100 \leqslant C_{90} \leqslant 200\right.$ cells $\left.\mathrm{mm}^{-2}\right)$, and low $\left(C_{90} \leqslant 100\right.$ cells mm $\left.^{-2}\right)$ within $0.5 \mathrm{~mm}$ from the implants. These three tumours showed comparable maximal distance of invasion $\left(D_{90}\right)$, but important differences in $C_{90}$ : $D 90$ and $C 90$ are two complementary estimates of invasion. 

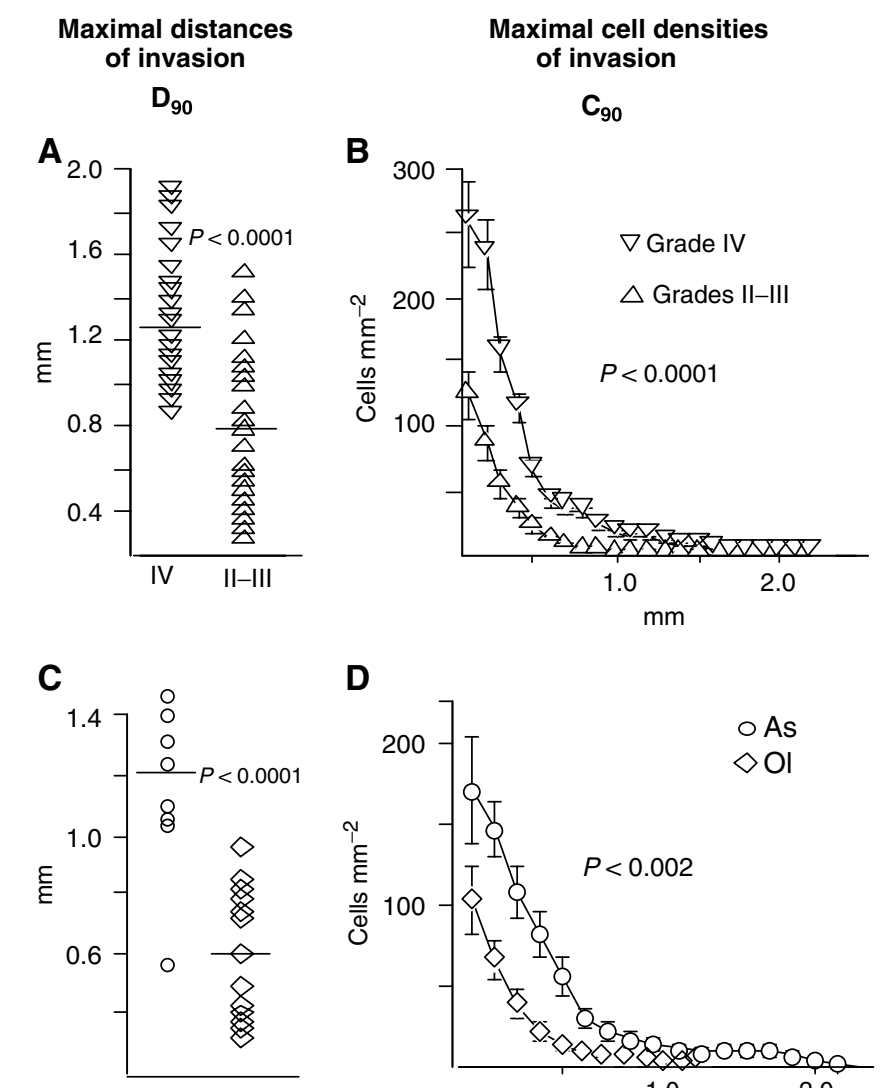

D
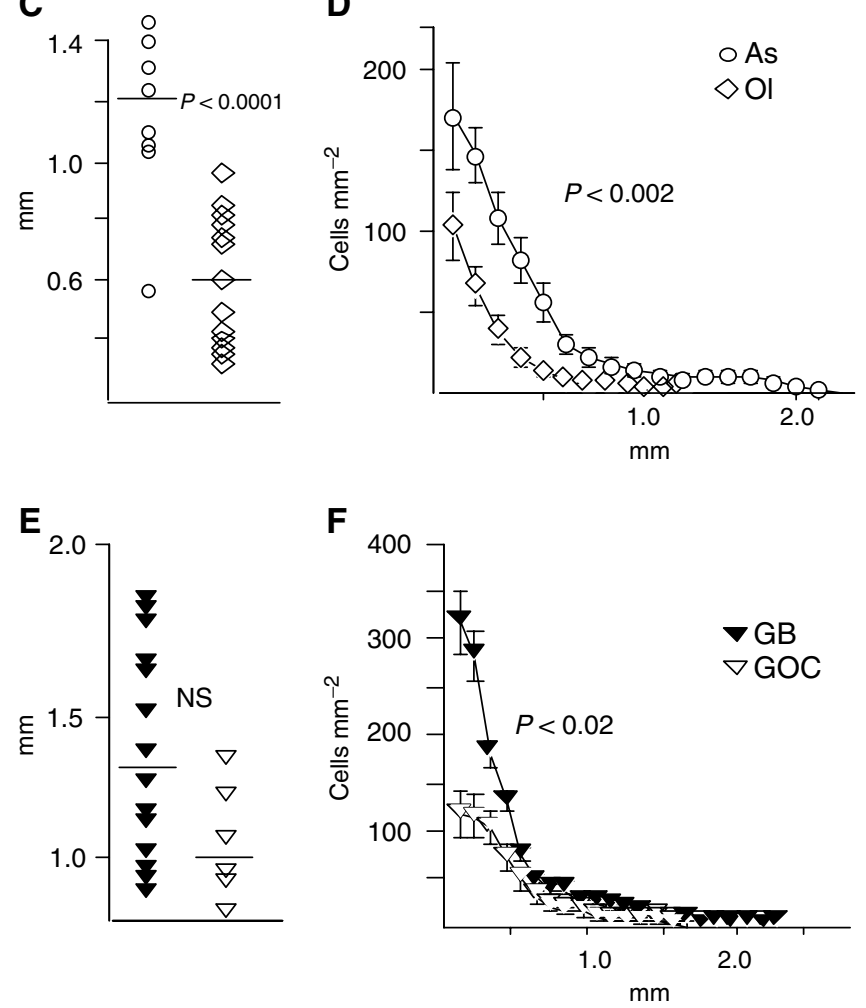

Figure $5 D_{90}$ and $C_{90}$ according to tumour grade $(\mathbf{A}, \mathbf{B})$ and tumour type $(\mathbf{C}-\mathbf{F})$. $D_{90}$ and $C_{90}$ were lower for grade II and III than for grade IV tumours $(\mathbf{A}, \mathbf{B})$, for grade II and III Ols than for grade II and III As (C,D); grade IV GOCs had lower $C_{90}$ than grade IV GBMs $(\mathbf{F})$, but the difference in $D_{90}(\mathbf{E})$ was not significant (Mann-Whitney test).

\section{In vitro infiltration and in situ growth}

The ratio MIB-1/caspase $3 \mathrm{LI}$ increased progressively with grade (Figure 7A), and tended to be higher for Ols and GOCs than for purely astrocytic tumours (Figure 7B). We examined this result in 32 additional grade II - IV gliomas selected from our files. Results obtained in this expanded series $(n=69)$ confirmed that grade II and grade III Ols had higher MIB-1/caspase 3 LIs ratios than As (Figure 7C).

The MIB1/caspase 3 ratio $(X), D_{90}(Y)$, and $C_{90}$ ( $Z$-axis) for each tumour were plotted separately for grade II and III (Figure 7D) and grade IV tumours (Figure 7E). This graphic analysis illustrated that
Table I Factor loadings (only values $\gg 0.5$ have been retained) resulting from the principal component analysis

\begin{tabular}{lccc}
\hline & Factor I & Factor 2 & Factor 3 \\
\hline Vessel density & +0.92 & - & - \\
Mibl/caspase 3 & +0.75 & - & - \\
Diffuse areas & - & -0.89 & - \\
Cell density & - & -0.87 & - \\
D90 & - & - & -0.74 \\
Ip/19q loss & - & -0.91 \\
\hline
\end{tabular}

Factor 1: vascular, in situ proliferative; Factor 2: hypercellular and compact (not diffuse); Factor 3: noninvasive, characteristic of tumours with $1 \mathrm{p} / 19 \mathrm{q}$ loss.

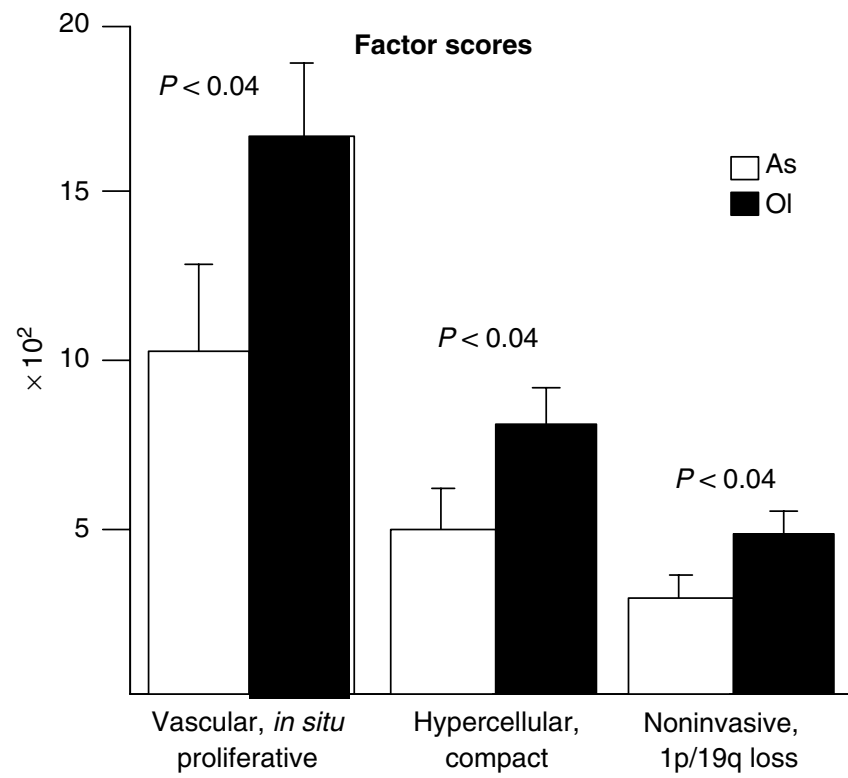

Figure 6 Factor scores of grade II and III As and Ols for the principal components extracted (Table I): 'vascular in situ proliferating' (factor I), 'hypercellular and compact' (factor 2), and 'noninvasive, characteristic of tumours with $I \mathrm{l} / \mathrm{I} 9 \mathrm{q}$ loss' (factor 3 ). Score for all the three factors were higher for Ols than for As (Mann-Whitney test).

infiltrative spread is predominant in grade II and III As, while in situ proliferation is predominant in Ols (Figure 7D). As documented in other studies (Rhodes, 1998), some GBMs could have very low proliferative potentials (Figure 7E), and presumably grow predominantly by infiltration.

\section{DISCUSSION}

The main result of the present study is that oligodendroglial tumours with $1 \mathrm{p} / 19 \mathrm{q}$ loss were less invasive in vitro than astrocytomas without deletions on these chromosomes. Correlation analysis of parameters measured ex vivo suggested that in vivo Ols may present relatively compact and hypercellular in situ proliferating masses, in contrast to the more diffuse, less proliferative, and more invasive As.

The ratio between cell spread and in situ proliferation is relevant to describe how gliomas are organised in space (Swanson et al, $2000,2002)$. Three patterns of glioma spatial organisation have been defined: type I (solid bulk tumour), type II (solid tumour plus a diffuse halo of infiltrating cells), and type III structures (diffuse cloud of cells, no solid bulk) (Kelly et al, 1987). The different ratios of infiltration and proliferation of grade II and III Ols and As 

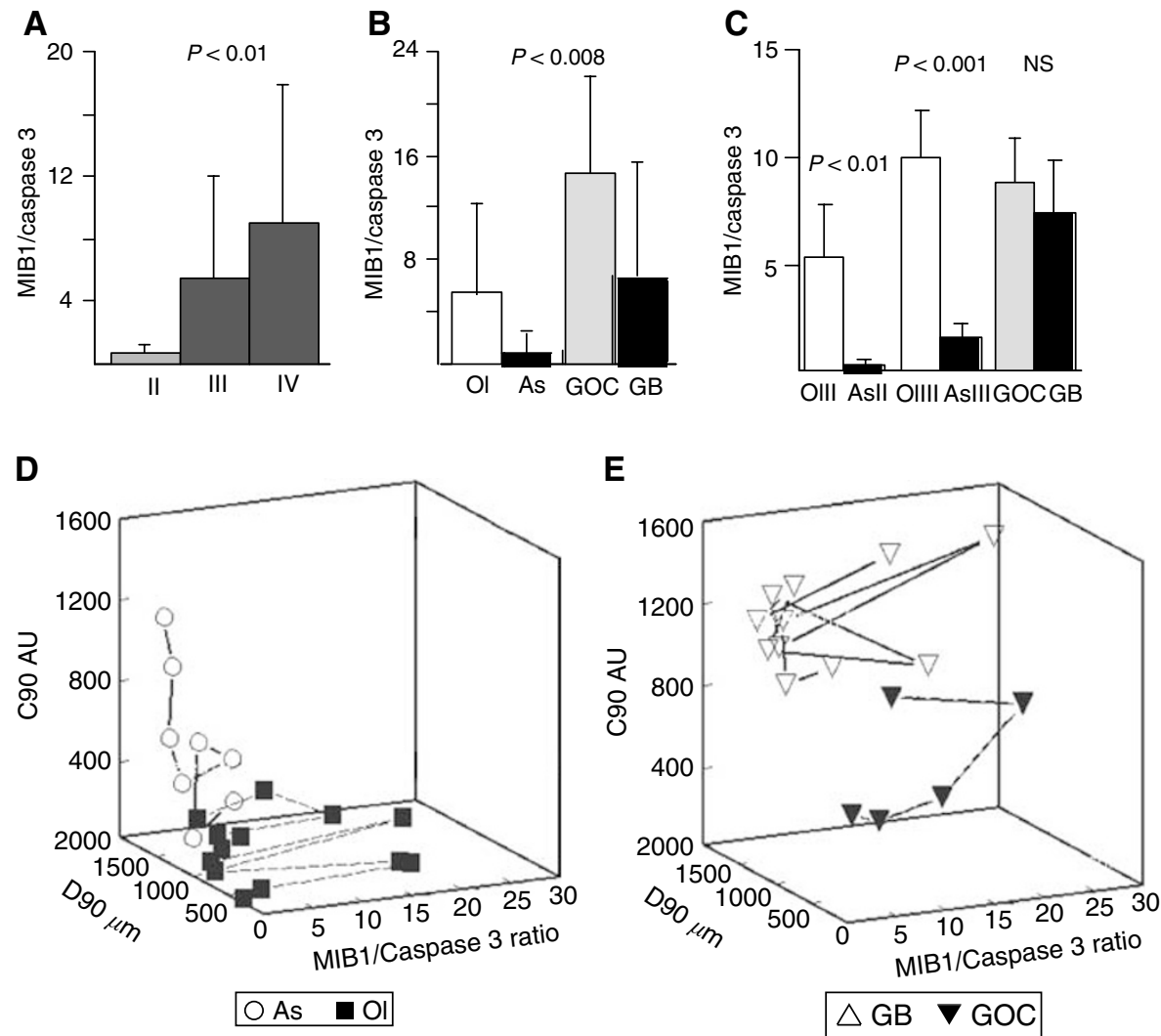

Figure 7 MIB-I/caspase 3 ratios of gliomas of different grade $(\mathbf{A})$ and type (B,C); three-dimensional plots - MIB-I/caspase 3 ratio (X), D90 (Y), C90 (Zaxis) - of grade II and III tumours (D) and grade IV tumours (E). (A) In situ proliferation increased with grade; (B) higher in situ proliferation potentials for Ols than for As and for GOCs than for GBMs were suggested for tumours studied in the invasion assay (Kruskal-Wallis test); (C) A larger series ( $n=69$ ) confirmed that grade II and grade III Ols had higher MIB- I/caspase 3 ratios than As of the same grade (Mann-Whitney test); (D) factors that determine the growth pattern of gliomas delineate important differences between the invasive As and the in situ proliferating Ols (grade II and III). (E) Note that some GBMs have very low proliferative potentials, and presumably grow predominantly by infiltration: knowledge of the infiltrative potential of a glioma is probably as important as knowledge of its capacity to proliferate.

demonstrated by multivariate analysis suggest that the spatial organisation of the less invasive Ols may correspond to type I or to type II with a limited diffuse component, while that of the more invasive As corresponds to more diffuse type II or to type III structures.

The in vitro invasion assay correlates to a large extent with aspects of glioma behaviour that are known to depend on the degree of invasion. For instance, the time to tumour progression after surgery (TTP) is thought to depend on the number of glioma cells infiltrating the resected margin which, in order to form a secondary growth, need to reach a critical cell density (Chicoine and Silbergeld, 1995; Burgess et al, 1997; Silbergeld and Chicoine, 1997). An astrocytic ( $v s$ oligodendroglial or mixed) phenotype has been found to be highly predictive of shorter TTP in 379 grade II glioma patients (Karim et al, 1996). Up to four times longer TTP was documented for $1 \mathrm{p} / 19 \mathrm{q}$ codeleted Ols than for tumours without these deletions (Fallon et al, 2004). Likewise, in a series of pure GBMs and GOCs, $90 \%$ of the patients with unusually long TTP had tumours with an oligodendroglial component (Kraus et al, 2000). Besides the numbers of invading cells, TTP could be influenced by spatial patterns. Imaging methods detect tumour bulks of a certain minimal cell density (the threshold cell density concept) (Burgess et al, 1997; Swanson et al, 2000), and this bulk is the target of surgery. The more compact and cellular the tumour (e.g. type I), the greater the likelihood of a larger resection (Swanson et al, 2002). Theoretically, tumour burden will remain greater post-surgery for diffuse hypocellular tumours (e.g. type III), since a smaller portion is identified and removed.
Patients with grade II and III Ols and OlAs have better prognosis than patients with As of the corresponding grade even in the absence of chemotherapy (Karim et al, 1996; Louis et al, 2001). Similarly, in several studies gliomas with grade IV histology and an oligodendroglial component have been associated with better prognosis than pure GBMs (Donahue et al, 1997; Kraus et al, $2000)$. There is a seeming contradiction between this evidence and results of comparative studies which have invariably documented higher proliferation (Deckert et al, 1989; Karamitopoulou et al, 1994; Schiffer et al, 1995; Gordower et al, 1998; Heesters et al, 1999, 2002; Geiger et al, 2000) and lower apoptotic rates (Geiger et al, 2000; Heesters et al, 2002) for Ols than for As of similar grade. Our results may help resolve this contradiction since models of glioma growth kinetics predict that growth by infiltration should be faster than growth by proliferation (Burgess et al, 1997). The opposition, from a kinetic point of view, between infiltration and proliferation may also have important biological underpinnings. There is evidence that migrating cells do not proliferate (Giese et al, 1996) because they downregulate genes involved in cell proliferation (Mariani et al, 2001). The concomitant upregulation of antiapoptotic programmes (Mariani et al, 2001; Joy et al, 2003) indicates that these nondividing cells may also be longer-lived. This particular kinetic profile of migrating cells should be taken into account by models studying the relationships between the infiltration and proliferation determinants of glioma growth.

The threshold cell density concept also explains why aggressiveness of gliomas should depend on high densities rather than on long distances of cell invasion. Low-grade gliomas disseminate to 
considerable distances in the brain, Ols invade the brain cortex forming secondary structures such as perineuronal (satellitosis) and subpial cell accumulations (Giese et al, 2003). If, however, invasion is of low (i.e. subthreshold) cell density, it would not result in clinical growth (Burgess et al, 1997). Indeed, $D_{90}$ values but not $C_{90}$ values overlapped between grade IV and grade II and III tumours.

The incidence of $1 p / 19 q$ loss reported here is in keeping with previous reports on GOCs (Kraus et al, 2001) and 'classic' Ols showing cells with clear halos and typical branching vessels (Sasaki et al, 2002, Watanabe et al, 2002) - 11 out of 13 grade II and III Ols and OlAs in this series contained area with these wellrecognised features. $1 \mathrm{p} / 19 \mathrm{q}$ codeleted classic Ols are associated with long survival (Fallon et al, 2004) and tend to evolve indolently even without treatment (van den Bent et al, 2003). Although tentatively, we speculate that this particular evolution may be due to limited infiltrative tumour growth. Ostensibly, the high proportion of 'classic' Ols' in our series calls for a comparison with Ols devoid of classic features. We, however, did not attempt to make this comparison, given the poor consensus on the histological definition of these tumours, amply illustrated in the recent literature (Fuller et al, 2003). Our results support the view that 'classic' Ols' may be a distinct glioma entity characterised by high incidence of $1 \mathrm{p} / 19 \mathrm{q}$ loss, limited invasive potential, and the kinetic profile of in situ proliferating, relatively circumscribed tumours.

In conclusion, we believe that our organotypic model of glioma invasion is a realistic tool providing information about the infiltrative potential of gliomas, a fundamental behavioural characteristic of these tumours, which has been difficult to analyse in quantitative terms.

\section{ACKNOWLEDGEMENTS}

This work was supported by the INSERM, Association pour la Recherche sur le Cancer (9032), Ligue Nationale contre le Cancer and fellowships from the Association Française de Recherche Génétique.

\section{REFERENCES}

Bigner SH, Matthews MR, Rasheed BK, Wiltshire RN, Friedman HS, Friedman AH, Stenzel TT, Dawes DM, McLendon RE, Bigner DD (1999) Molecular genetic aspects of oligodendrogliomas including analysis by comparative genomic hybridisation. Am J Pathol 155: 375-386

Burgess PK, Kulesa PM, Murray JD, Alvord EC (1997) The interaction of growth rates and diffusion coefficients in a three-dimensional mathematical model of gliomas. J Neuropathol Exp Neurol 56: 704-713

Chicoine MR, Silbergeld DL (1995) The in vitro motility of human gliomas increases with increasing grade of malignancy. Cancer 75: 2904-2909

de Boüard S, Christov C, Guillamo JS, Kassar-Duchossoy L, Palfi S, Masset M, Cohen-Hagenauer O, Peschanski M, Lefrançois T (2002) Ivasion of human glioma biopsies in rodent brain slices: a quantitative analysis. J Neurosurg 97: 169-176

Deckert M, Reifenberger G, Wechsler W (1989) Determination of the proliferative potential of human brain tumours using the monoclonal antibody Ki-67. J Cancer Res Clin Oncol 115: 179-188

Donahue B, Scott CB, Nelson JS, Rotman M, Murray KJ, Nelson DF, Banker FL, Earle JD, Fischbach JA, Asbell SO, Gaspar LE, Markoe AM (1997) Influence of an oligodendroglial component on the survival of patients with anaplastic astrocytomas: a report of Radiation Therapy Oncology Group 83-02. Int J Radiat Oncol Biol Phys 38: 911 -914

Fallon KB, Palmer CA, Roth KA, Nabors LB, Wang W, Carpenter M, Banerjee R, Forsyth P, Rich K, Perry A (2004) Prognostic value of 1p, $19 \mathrm{q}, 9 \mathrm{p}, 10 \mathrm{q}$, and EGFR-FISH analyses in recurrent oligodendrogliomas. J Neuropathol Exp Neurol 63: 314-322

Fuller CE, Schmidt RE, Roth KA, Burger PA, Scheithauer BW, Banerjee R, Trinkaus K, Lytle R, Perry A (2003) Clinical utility of fluorescence in situ hybridization (FISH) in morphologically ambiguous gliomas with hybrid oligodendroglial/astrocytic features. I Neuropathol Exp Neurol 62: $1118-1128$

Geiger KD, Stoldt P, Schlote W, Derouiche A (2000) Ezrin immunoreactivity is associated with increasing malignancy of astrocytic tumours but is absent in oligodendrogliomas. Am J Pathol 157: 1785-1793

Giese A, Bjerkvig R, Berens ME, Westphal M. (2003) Cost of migration: invasion of malignant gliomas and implications for treatment. J Clin Oncol 21: $1624-1636$

Giese A, Loo MA, Tran N, Haskett D, Coons SW, Berens ME (1996) Dichotomy of astrocytoma migration and proliferation. Int J Cancer 67: $275-282$

Gordower L, Decaestecker C, Lopez M-B, Camby I, Nagy N, François C, Cras P, Martin J-J, Brotchi J, Kisss R, Salmon I (1998) Determination of the growth fraction and cell density to evaluate the potential growth of human oligodendroglial and astrocytic tumours. J Cancer Res Clin Oncol 124: $427-434$

Guillamo JS, Lisovoski F, Christov C, Le Guerinel C, Defer GL, Peschanski M, Lefrancois T (2001) Migration pathways of human glioblastoma cells xenografted into the immunosuppressed rat brain. J Neurooncol 52: 205-215
Heesters MA, Koudstaal J, Go K, Molenaar WM (1999) Analysis of proliferation and apoptosis in brain gliomas: prognostic and clinical value. J Neurooncol 44: 226-255

Heesters MA, Koudstaal J, Gwan Go K, Molenaar WM (2002) Proliferation and apoptosis in long term surviving low grade gliomas in relation to radiotherapy. I Neurooncol 58: 157-165

Joy AM, Beaudry CE, Tran NL, Ponce FA, Holz DR, Demuth T, Berens ME (2003) Migrating glioma cells activate the PI3-K pathway and display decreased susceptibility to apoptosis. J Cell Sci 116: 4409-4417

Jung S, Ackerley C, Ivanchuk S, Monda S, Becker LE, Rutka JT (2001) Tracking the invasiveness of human astrocytoma cells by using green fluorescent protein in an organotypical brain slice model. J Neurosurg 94: $80-89$

Karamitopoulou E, Perentes E, Diamantis I, Maraziotis T (1994) Ki-67 immunoreactivity in human central nervous system tumours: a study with MIB 1 monoclonal antibody on archival material. Acta Neuropathol (Berl) 87: 47-54

Karim AB, Maat B, Hatlevoll R, Menten J, Rutten EH, Thomas DG, Mascarenhas F, Horiot JC, Parvinen LM, van Reijn M, Jager JJ, Fabrini MG, van Alphen AM, Hamers HP, Gaspar L, Noordman E, Pierart M, van Glabbeke M (1996) A randomized trial on dose-response in radiation therapy of low-grade cerebral glioma: European Organization for Research and Treatment of Cancer (EORTC) Study 22844. Int $J$ Radiat Oncol Biol Phys 36: 549-556

Kelly PJ, Daumas-Dupor C, Scheithauer BW, Kal BA, Kispert DB (1987) Stereotactic histologic correlations of computed tomography- and magnetic resonance imaging-defined abnormalities in patients with glial neoplasms. Mayo Clin Proc 62: 450-459

Kleihues P, Louis DN, Scheithauer BW, Rorke LB, Reifenberger G, Burger PC, Cavenee WK (2002) The WHO classification of tumours of the nervous system. J Neuropathol Exp Neurol 61: 215-225

Kraus JA, Lamszus K, Glesmann N, Beck M, Wolter M, Sabel M, Krex D, Klockgether T, Reifenberger G, Schlegel U (2001) Molecular genetic alterations in glioblastomas with oligodendroglial component. Acta Neuropathol (Berl) 101: $311-320$

Kraus JA, Wenghoefer M, Schmidt MC, von Deimling A, Berweiler U, Roggendorf W, Diete S, Dietzmann S, Müller B, Heuser K, Reifenberger G, Schlegel U (2000) Long-term survival of glioblastoma multiforme: importance of histopathological reevaluation. J Neurol 247: $455-460$

Louis DN, Holland EC, Cairncross JG (2001) Glioma classification: a molecular reappraisal. Am J Pathol 159: 779-786

Mariani L, Beaudry C, McDonough WS, Hoelzinger DB, Demuth T, Ross KR, Berens T, Coons SW, Watts G, Trent JM, Wei JS, Giese A, Berens ME (2001) Glioma cell motility is associated with reduced transcription of proapoptotic and proliferation genes: a cDNA microarray analysis. J Neurooncol 53: 161 - 176 
McKeown MJ, Ramsay DA (1996) Classification of astrocytomas and malignant astrocytomas by principal components analysis and a neural net. J Neuropathol Exp Neurol 55: 1238-1245

Murakami M, Goto S, Yoshikawa M, Goto T, Hamasaki T, Rutka JT, Kuratsu JI, Ushio Y (2001) The invasive features of glial and non-central nervous system tumour cells are different on organotypic brain slices from newborn rats. Int J Oncol 18: 717-721

Rhodes RH (1998) Biological evaluation of biopsies from adult cerebral astrocytomas: cell-growth/cell-suicide ratios and their relationship to patient survival. J Neuropathol Exp Neurol 57: 746-757

Sasaki H, Zlatescu MC, Betensky RA, Johnk LB, Cutone AN, Cairncross JG, Louis DN (2002) Histopathological-molecular genetic correlations in referral pathologist-diagnosed low-grade 'oligodendroglioma'. J Neuropathol Exp Neurol 61: 58-63

Schiffer D, Cavalla P, Migheli A, Chio A, Giordana MT, Marino S, Attanasio A (1995) Apoptosis and cell proliferation in human neuroepithelial tumours. Neurosci Lett 195: $81-84$

Schiffer D, Fiano V, Chiado-Piat L, Mortara P, Richiardi P, Cavalla P (2001) Distribution of activated caspase- 3 in relation with apoptosis in human malignant gliomas. Neurosci Lett 300: 37-40
Silbergeld DL, Chicoine MR (1997) Isolation and characterization of human malignant glioma cells from histologically normal brain. J Neurosurg $\mathbf{8 6}$ $525-531$

Swanson KR, Alvord Jr EC, Murray JD (2000) A quantitative model for differential motility of gliomas in grey and white matter. Cell Prolif 33: $317-329$

Swanson KR, Alvord Jr EC, Murray JD (2002) Virtual brain tumours (gliomas) enhance the reality of medical imaging and highlight inadequacies of current therapy. $\mathrm{Br} J$ Cancer 86: $14-18$

UKCCR (1998) United Kingdom Co-ordinating Committee on Cancer Research guidelines for the welfare of animals in experimental neoplasia, 2nd edn. Br J Cancer 77: 1 - 10

van den Bent MJ, Looijenga LH, Langenberg K, Dinjens WNM, Graveland WJ, Uytdewilligen L, Sillevis Smith PAE, Jenkins RB, Kros JM (2003) Chromosomal anomalies in oligodendroglial tumours are correlated to clinical features. Cancer 97: 1276-1284

Watanabe T, Nakamura M, Kros JM, Burkhard C, Yonekawa Y, Kleihues P, Ohgaki H (2002) Phenotype versus genotype correlation in oligodendrogliomas and low-grade diffuse astrocytomas. Acta Neuropathol (Berl) 103: $267-275$ 